\title{
O PROCESSO CONSTITUCIONAL E A PROTEÇÃO DOS DIREITOS FUNDAMENTAIS NO ESTADO DEMOCRÁTICO DE DIREITO
}

\author{
THE CONSTITUTIONAL PROCESS AND THE FUNDAMENTAL RIGHTS PROTECTION \\ ON DEMOCRATIC STATE OF LAW
}

\begin{abstract}
Ana Paula Brandão Ribeiro
Mestre em Direito Processual pela Pontifícia Universidade Católica de Minas Gerais - PUC Minas. Professora na Faculdade Arquidiocesana de Curvelo (FAC). E-mail: anapbr07@gmail.com
\end{abstract}

Isabella Carolina Miranda

Graduada em Direito pela Pontifícia Universidade Católica de Minas Gerais - PUC Minas e advogada no escritório Gilberto José Vaz Advogados. E-mail: isabella.cmiranda@yahoo.com.br

Recebido em: 26/04/2014

Aprovado em: 12/02/2016

Doi: $10.5585 / \mathrm{rdb} . v 14 \mathrm{i} 6.154$

RESUMO: Este trabalho objetiva demonstrar a importância dos direitos fundamentais, enquanto direitos humanos constitucionalizados, no Estado Democrático de Direito. Ainda, busca enfatizar que a mera positivação, ainda que constitucionalizada desses direitos, não lhes confere concretização direta e imediata, razão pela qual indispensável a criação de garantias fundamentais. Diferenciar os institutos direitos fundamentais e garantias fundamentais, inclusive, é uma das preocupações deste trabalho. O presente trabalho busca apresentar, ainda, a conceituação de Estado Democrático de Direito, trabalhar questões afetas aos direitos e garantias fundamentais e, como consequência lógica, proceder-se-á ao estudo do Processo Constitucional e do seu grau máximo de importância para a proteção dos direitos fundamentais no Estado Democrático de Direito. Em suma, estudar o Processo Constitucional e a proteção dos direitos fundamentais no Estado Democrático de Direito é, portanto, o objetivo que se propõe nesta pesquisa.

Palavras-Chave: Direitos fundamentais. Processo Constitucional. Estado Democrático de Direito.

\begin{abstract}
This work aims to demonstrate the importance of fundamental rights as constitutionalized human rights in a Democratic State of Law. It also seeks to emphasize that the mere positivization, even under a constitutionalized version, does not give those rights direct and immediate implementation, which is why it is essential to establish basic safeguards. Distinguishing fundamental rights from basic guarantees, in fact, is one of the concerns of this work. This paper also presents the concept of a Democratic State of Law, debates issues regarding fundamental rights and guarantees and, as a logical consequence, goes along a study of the Constitutional Process and its maximum importance degree to the fundamental rights protection in a Democratic State of Law. In short, studying the Constitutional Process and the
\end{abstract}


fundamental rights protection in Democratic State of Law is therefore the goal which is proposed in this research.

Keywords: Fundamental rights. Constitutional Process. Democratic State of Law.

SUMÁRIO: Introdução; 1. Um gosto especial por regras; 2. Traduzindo decisões em normas (que se parecem com regras); 3. O Supremo Tribunal Federal e certo desleixo com os precedentes; Conclusão; Bibliografia; Sítios virtuais.

\section{INTRODUÇÃO}

A Constituição da República Federativa do Brasil instituiu o Estado Democrático de Direito como sistema jurídico-normativo, norteador de todas as ações (omissivas ou comissivas) deste novo Estado que ali acabara de se aflorar.

Fruto dos anseios de uma comunidade devassada pela Segunda Guerra Mundial, o Estado Democrático de Direito, formado pela conexão entre o Estado de Direito e o Estado Democrático, objetiva limitar o poder estatal e, consequentemente, preservar a liberdade do povo, enquanto sujeito constitucional legitimado ao processo.

Nesse novo cenário jurídico, os direitos humanos foram constitucionalizados, passando a adquirir o status de direitos fundamentais.

Entretanto, a mera positivação, ainda que constitucionalizada desses direitos, não lhes confere concretização direta e imediata. Assim, necessária se fez a criação de garantias fundamentais.

Considerando que direitos e garantias fundamentais estão interligados, por certo que houve - e há - a confusão terminológica e interpretativa dos dois institutos, que não raras vezes são tratados como sinônimos. Tal confusão, inclusive, é uma das preocupações deste trabalho, cuja diferenciação será oportunamente apresentada.

Tanto os direitos quanto as garantias fundamentais são indispensáveis ao estudo do Processo. E este, sob o pano de fundo do Estado Democrático de Direito, necessariamente vincula-se à Constituição.

Assim, o instituto que pode tanto garantir a preservação dos direitos fundamentais quanto ofertar condições e métodos para a sua concretização não é outro senão o Processo Constitucional.

Nessa linha de raciocínio, o presente trabalho busca apresentar a conceituação de Estado Democrático de Direito, não descartando a importância dos paradigmas precedentes. Serão trabalhadas também questões afetas aos direitos e garantias fundamentais. E, como consequência lógica, proceder-se-á ao estudo do Processo Constitucional e do seu grau máximo de importância para a proteção dos direitos fundamentais no Estado Democrático de Direito.

Estudar o Processo Constitucional e a proteção dos direitos fundamentais no Estado Democrático de Direito é, portanto, o objetivo proposta por essa pesquisa. 


\section{O ESTADO DEMOCRÁTICO DE DIREITO: DA RELEITURA DOS PARADIGMAS PRECEDENTES}

$1988^{1}$.

Estado Democrático de Direito: este é o paradigma eleito pela Constituição Brasileira de

Já de início é importante destacar que o termo "paradigma" deve ser lido e interpretado de maneira crítica, de modo a se afastar a ideia simplista de "modelo" ou "padrão" que acabam por deixar à margem os ganhos teóricos dos "paradigmas" anteriores. Assim, ressalta-se o conceito do termo apresentado por Ronaldo Brêtas de Carvalho Dias:

[...] paradigmas de Estado de Direito e do Estado Democrático de Direito devem ser compreendidos como sistemas jurídico-normativos consistentes, concebidos e estudados pela teoria do Estado e pela teoria constitucional, no sentido técnico de verdadeiros complexos de ideias, princípio e regras juridicamente coordenados, relacionados entre si por conexão lógico formal, informadores da moderna concepção de Estado e reveladores das atuais tendências científicas observadas na sua caracterização e estruturação jurídico-constitucional. (BRÊTAS, 2010, p. 55).

Em relação aos aludidos ganhos teóricos dos paradigmas precedentes, são estes necessários à dinâmica jurídica (LEAL, 2002, p. 25), na medida em que ofertam conceituação e grau de importância, tanto do Estado quanto dos direitos fundamentais, para o processo de integração social.

Dierle Nunes também é adepto à teoria de que os paradigmas precedentes não podem ser excluídos como se nenhuma contribuição tivessem deixado ou trazido para o atual paradigma do Estado Democrático de Direito. O referido autor ensina que "na busca de uma efetiva democratização jurídica no processo jurisdicional, faz-se mister uma articulação conjunta das conquistas técnicas dos processos liberal e social" (2009, p. 360). Ainda segundo o mencionado autor, deve ser feita uma releitura (2011, p. 136) dos modelos anteriores, sustentada numa visão democrática, objetivando-se evitar os problemas anteriormente verificados.

O grau de aproveitamento e ou das contribuições que os paradigmas anteriores ofereceram e oferecem ao atual Estado Democrático de Direito é traduzido pelas lições de Marcelo Cattoni:

No esteio dos novos movimentos sociais, tais como o estudantil de 1968, o pacifista, o ecologista e os de luta pelos direitos das minorias, além dos movimentos contra culturais, que passa a eclodir a partir da segunda metade da década de 60, a "nova esquerda", a chamada esquerda não-estalinista, a partir de duras críticas tanto ao Estado de Bem-Estar - denunciando os limites e o alcance das políticas públicas, as contradições entre o capitalismo e democracia -, quanto ao Estado de socialismo real - a formação de uma burocracia autoritária, desligada das aspirações populares -, cunha a expressão Estado Democrático de Direito. (CATTONI, 1998, p. 132).

Assim é que as concepções dos paradigmas anteriores são de grande importância para o atual Estado Democrático de Direito. Não por repetições ou exclusões inquestionáveis, mas porque tais concepções, com a Constituição de 1988, suplicam revitalização (DEL NEGRI, 2009, p. 72).

\footnotetext{
${ }^{1}$ Art. $1^{\circ}$ da Constituição da República Federativa do Brasil: "A República Federativa do Brasil, formada pela união indissolúvel dos Estados e Municípios e do Distrito Federal, constitui-se em Estado Democrático de Direito [...]". BRASIL. Constituição (1988). Constituição da República Federativa do Brasil. Brasília: Senado, 1988.

Revista de Direito Brasileira | São Paulo, SP | v. 14 | n. 6 | p. 139 - 157 | maio/ago. 2016
} 
Partindo desta assertiva, podemos nos reportar à doutrina de Ronald Dworkin, em sua hipótese estética da literatura. Isto porque, da mesma forma que Dworkin entende que o Direito se assemelha à literatura ${ }^{2}$, na medida em que esteja pronto a reformular soluções que não se amoldam a determinado contexto, igualmente é possível conceber os paradigmas anteriores ao Estado Democrático de Direito. Como acima afirmado, é inegável que aqueles, direta ou indiretamente, contribuíram e contribuem para o atual contexto jurídico. Entretanto, eles (o Estado de bem-estar e o Estado de socialismo real) devem ser relidos, buscando extrair-lhes aquilo que de melhor podem oferecer (DWORKIN, 2005, p. 221).

Assim, não foi por outra razão que Karl Raimund Popper afirmou em sua obra A lógica da pesquisa científica que "não pode haver, em ciência, enunciado insuscetível de teste e, consequentemente, enunciado que não admita, em princípio, refutação pelo falseamento de algumas das conclusões que dele possam ser deduzidas" (2006, p. 49).

Portanto, os paradigmas precedentes ao Estado Democrático de Direito, em maior ou menor grau, de maneira direita ou indireta, contribuíram para o florescimento deste, eleito pela Constituição da República Federativa do Brasil de 1988.

\subsection{DA CONCEITUAÇÃO DO ESTADO DEMOCRÁTICO DE DIREITO}

Uma vez tecida a observação necessária acerca do termo "paradigma" - enquanto erroneamente entendido simplesmente como "modelo", "padrão", "matriz" ou qualquer outra palavra sinônima -, este trabalho, por questões meramente didáticas, passará a utilizar referido termo, porém, no sentido crítico acima abordado.

Tecidas tais considerações, passemos à conceituação da expressão Estado Democrático de Direito, à luz da construção de alguns juristas, doutrinadores e estudiosos do Direito.

Gilmar Ferreira Mendes, Inocêncio Mártires Coelho e Paulo Gustavo Gonet Branco partem do entendimento de que tal sistema jurídico-normativo é uma organização política, cujo poder emana do povo (MENDES, MÁRTIRES COELHO, GONET BRANCO, 2008. p. 149). Neste sistema, o exercício do poder político é conferido diretamente ou por representantes, eleitos pelo voto direto e secreto. Já na relação entre o poder e a pessoa constitucional (cidadão), é democrático aquele Estado que assegura direitos, tanto civis e políticos quanto sociais, econômicos e culturais.

Habermas, citado por André Del Negri, apresenta uma definição de Estado Democrático de Direito que, embora sucinta em seu conteúdo literal, possui um enorme e real significado, qual seja, de "projeto inacabado e em constante construção" (2008, p. 67).

O professor Rosemiro Pereira Leal conceitua Estado Democrático como sendo a "instituição estabilizadora da preservação do espaço processual de recriação e revisibilidade permanente do ordenamento jurídico pela comunidade (povo)" (2011, p. 237). Ou, em outras palavras, Estado Democrático de Direito significa nada mais que Estado não dogmático.

O professor Ronaldo Brêtas de Carvalho Dias ${ }^{3,}$ parte do entendimento de que o Estado Democrático de Direito é um macro princípio, formado a partir da conexão entre outros dois princípios ${ }^{4}$, o Estado de Direito e o Estado Democrático. Estes, de maneira equilibrada, buscam

\footnotetext{
${ }^{2}$ Sobre o tema, ver capítulo 6 da obra Uma Questão de Princípio. Trad. Luís Carlos Borges. $2^{\text {a }}$ ed. São Paulo: Martins Fontes, 2005.

${ }^{3}$ Sobre o tema, ver: BRÊTAS, Ronaldo de Carvalho Dias. Processo Constitucional e Estado Democrático de Direito. Belo Horizonte: Del Rey, 2010. p. 48-65.

${ }^{4}$ O princípio, segundo Antônio Cota Marçal, "é uma construção teórica integradora, na medida em que é o resultado de uma generalização, que reúne e organiza outros e anteriores conhecimentos e, como tal, permite compreender e explicitar a correlação entre conhecimentos e realidade conhecida. O princípio é, neste processo, também uma construção conceitual operativa, na medida em que os conhecimentos nele reunidos e expressos possibilitam Revista de Direito Brasileira | São Paulo, SP | v. 14 | n. 6 | p. 139 - 157 | maio/ago. 2016
} 
obter um Estado organizado, com poderes limitados, de maneira a se garantir a liberdade dos destinatários do poder político. Neste sentido, pode-se afirmar, inclusive, que o Estado se legitima na Constituição ${ }^{5}$.

Não fosse assim, certo é que haveria, conforme bem afirmado por Del Negri, uma

Extrema arbitrariedade e também uma superioridade do Estado sobre o indivíduo, tomando características de um Estado hegeliano, o qual não obtém a soberania do Povo, mas de si próprio, que vê os cidadãos apenas como um componente de formação estatal. (DEL NEGRI, 2009, p. 36-37).

Lênio Luiz Streck afirma que "a profissão de fé dos juristas na democracia depende de um Estado Democrático de Direito" (2009, p. 5).

Assevera, ainda, Humberto Theodoro Júnior, acerca do tema, que "o Estado Democrático de Direito não pode apenas garantir a tutela jurisdicional, mas tem de assegurar uma tutela qualificada pela fiel observância dos direitos fundamentais consagrados constitucionalmente" (2009, p. 259).

Hermes Zanetti Júnior, por sua vez, parece entender de forma contrária, ao afirmar em sua obra, expressamente, que "o Estado Democrático de Direito, também chamado agora Estado Constitucional Democrático sobressai da evolução histórica do Estado Social, que agregou o elemento participativo"6 (2007, p. 113). Aqui, com o devido respeito acadêmico ao autor, cabe uma crítica: a conceituação por ele exposta conduz o leitor a concluir que o Estado Democrático de Direito, além de ser algo pronto e acabado, surgiu por osmose do Estado Social, e não como fruto de um processo contínuo de construção. Além disso, entende o autor que o Estado Democrático de Direito seria tão somente um Estado Social diferenciado pelo elemento participativo; elemento este que, a partir da conceituação estabelecida pelo citado autor, parece surgir, igualmente, por osmose, de um paradigma anterior. Assim, entendemos que o conceito de Estado Democrático de Direito apresentado por Hermes Zanettti Júnior, além de colocar à margem as contribuições dos Estados precedentes, por certo que destoa, sobremaneira, do sistema jurídico-normativo contemporâneo, eleito pela Constituição Brasileira de 1988.

Neste sentido, Estado Democrático de Direito não é modelo ou matriz disciplinar, mas antes, um grande princípio reluzente, fruto da articulação dos princípios do Estado Democrático e

progredir na produção de novos conhecimentos e também orientar a forma e o curso da ação humana voltada para fins". MARÇAL, Antônio Cota. Princípio - Estatuto, Função e Usos no Direito. In: TAVARES, Fernando Horta (Coord.). Constituição, Direito e Processo: Princípios Constitucionais do Processo. Curitiba: Juruá, 2008. p. 34. Humberto Ávila, por sua vez, afirma que os princípios são "normas que atribuem fundamento a outras normas, por indicarem fins a serem promovidos, sem, no entanto, preverem o meio para a sua realização". E prossegue, negando que os princípios não podem ser tidos apenas como valores, na medida em que eles "instituem o deve de adotar comportamentos necessários à realização de um determinado estado de coisas", ou seja, estabelecem espécies precisas de comportamentos. ÁVILA, Humberto. Teoria dos Princípios: da definição à aplicação dos princípios jurídicos. 13 ${ }^{\mathrm{a}}$ ed rev. e ampl. São Paulo: Malheiros, 2012. p. 136 e 141. De inegável importância e precisão é o conceito estabelecido por Ronaldo Brêtas de Carvalho Dias, para quem “os princípios são havidos como proposições fundamentais do Direito, via de consequiência, considerados normas jurídicas e, ao lado das regras, como idêntica força vinculativa, integram o ordenamento jurídico". BRÊTAS, Ronaldo de Carvalho Dias. Processo Constitucional e Estado Democrático de Direito. Belo Horizonte: Del Rey, 2010. p. 105.

${ }^{5}$ Simone Goyard-Fabre ensina que a Constituição deve ser tida como lei fundamental, na medida em que ela é, sem dúvidas, "a garantia dos direitos e das liberdades". Além disso, a referida autora afirma que a Constituição "é o estatuto matriarcal da institucionalização que, materialmente, estende-se a todos os campos da vida social". Daí, conclui que "uma lei ou um enunciado de direito só são válidos se são congruentes com o dispositivo da Constituição, que ganha assim valor de lei fundamental". GOYARD-FABRE, Simone. Os fundamentos da ordem jurídica. Trad. Cláudia Berlener, São Paulo: Martins Fontes, 2002. p. 126.

${ }^{6}$ Os grifos não se encontram no original, tendo sido por nós utilizados, no intuito de se enfatizar a visão do autor distinta da apresentada por este trabalho.

Revista de Direito Brasileira | São Paulo, SP | v. 14 | n. 6 | p. 139 - 157 | maio/ago. 2016 
Estado de Direito (BRÊTAS, 2012, p. 121-130), em torno do qual giram os demais princípios, uma vez que se busca, através deste Estado, assegurar o exercício pleno de direitos sociais e individuais, como valores supremos de uma sociedade pluralista.

A partir desta perspectiva, forçoso concluir que o Estado Democrático de Direito, paradigma regente de toda prática jurídica, norteia (ou ao menos deve nortear) a estruturação de todo o sistema jurídico. Devendo este norte ser observado em todas as fases de estruturação do sistema, mesmo porque, o princípio da supremacia da Constituição e o controle de constitucionalidade irrestrito das leis ${ }^{7}$ exigem tal observância.

\section{DIREITOS FUNDAMENTAIS}

Direitos fundamentais, em conceito sucinto, são as bases do Direito ${ }^{8}$, ou as garantias de proteção (FILHO, 2008, p. 36) definidas pela Constituição, originadas, principalmente, de reivindicações geradas a partir de situações de verdadeiro flagelo humano, como aquele verificado na Segunda Guerra Mundial ${ }^{9}$.

Mário Lúcio Quintão Soares chega a afirmar que os Direitos Fundamentais representam uma das bases ou princípio concretizadores do Estado Democrático de Direito ${ }^{10}$.

Considerando-se que o movimento expressivo de constitucionalização do processo (que chegou ao ponto de gerar uma teoria) ocorreu somente após a Segunda Guerra Mundial, forçoso concluir que os direitos fundamentais são essencialmente constitucionais. Isto porque, além de seu aflorar se encontrar diretamente ligado ao constitucionalismo (já teorizado), certo é que referidos direitos se encontram incorporados em todas as normas infraconstitucionais, não passando despercebidos em nenhuma delas. Razão pela qual hoje são eles constitutivos da própria forma do Direito (CARVALHO NETTO, 2011, p. 99).

Dimitri Dimoulis e Leonardo Martins definem os direitos fundamentais como sendo

[...] direitos público-subjetivos de pessoas (físicas ou jurídicas), contidos em dispositivos constitucionais e, portanto, que encerram caráter normativo supremo dentro do Estado, tendo como finalidade limitar o exercício do poder estatal em face da liberdade individual. (DIMOULIS; MARTINS, 2011, p. 49).

Acerca da terminologia utilizada na conceituação acima exposta (direitos públicosubjetivos), importante a contribuição de Cristina Queiroz (2010, p. 186), ao afirmar que os direitos fundamentais devem ser compreendidos e interpretados para além deste conceito tradicional. Isto porque a interpretação dos referidos direitos público-subjetivos deve ser feita em prol de uma compreensão constitucional, a partir da qual os direitos fundamentais deverão ser tidos como valores de proteção, constitucionalmente reconhecidos.

\footnotetext{
7 Ambos os dois princípios lembrados por Dhenis Cruz Madeira. Neste sentido, ver: MADEIRA, Dhenis Cruz. Processo de Conhecimento e Cognição: uma inserção no Estado Democrático de Direito. Curitiba: Juruá Editora, 2008, p. 35 .

${ }^{8}$ Expressão utilizada por Menelick de Carvalho Netto e Guilherme Scotti. CARVALHO NETTO; Menelick de.; SCOTTI, Guilherme. Os direitos fundamentais e a(in)certeza do direito: a produtividade das tensões principiológicas e a superação do sistema de regras.Belo Horizonte: Fórum, 2011. p. 92.

9 Vale aqui constar que o pós Segunda Guerra Mundial, com o seu resultado humano desastroso, necessariamente impulsionou a reconstrução do Direito. Referido cenário de calamidade representou, por sua vez, a gênese do Estado Democrático de Direito, conforme afirmado por Humberto Theodoro Júnior: "A reconstrução do direito europeu pós-Segunda Guerra, de que nasceu o contemporâneo Estado Democrático de Direito, reservaria ao contraditório papel muito mais amplo do que a simples audiência bilateral”. (2009, p. 252). (Grifos nossos).

${ }^{10}$ Sobre o tema, ver Capítulo 13 da obra: SOARES, Mário Lúcio Quintão. Teoria do Estado: o substrato clássico e os novos paradigmas como pré-compreensão para o Direito Constitucional. Belo Horizonte: Del Rey, 2001.
}

Revista de Direito Brasileira | São Paulo, SP | v. 14 | n. 6 | p. 139 - 157 | maio/ago. 2016 
Outro conceito acerca do termo direitos fundamentais é trazida por Ruy Alves Henriques Filho, para quem referidos direitos, constitucionais, devem ser compreendidos, primeiramente, como "elementos definidores e legitimadores de toda a ordem jurídica positiva" para, posteriormente, serem compreendidos "numa dimensão técnica de limitação do poder do Estado" (2008, p. 42).

Em estrita consonância com o conceito apresentado por Paulo Bonavides, pode-se concluir que os direitos fundamentais "são a bússola das Constituições" (2002, p. 600) e, de acordo com Rosemiro Pereira Leal, sendo eles "líquidos, certos e exigíveis" (2009, p. 288).

Independente da forma como são conceituados, urge aqui deixar em evidência que os direitos fundamentais não somente vinculam o poder político quanto, igualmente, vinculam os particulares, direta, linear e absolutamente. E, ainda, são limitados, no intuito de tornar possível a própria efetividade e concomitância prática destes direitos fundamentais ${ }^{11}$.

\subsection{DESMISTIFICAÇÃO DOS DIREITOS FUNDAMENTAIS}

Hodiernamente, ainda se concebe os direitos fundamentais como algo vindo de um materialismo histórico, tão somente. Neste viés, referidos direitos são encontrados no recinto do pragma $^{12}$.

Entender os direitos fundamentais neste sentido, como destino histórico, trata-se de evidente equívoco, uma vez que se verifica algo puramente retórico.

Além disso, os direitos fundamentais, nessa mesma perspectiva, ainda cultuam précompreensões pela nostalgia rousseauneana de uma sociedade hipotética encontrada pelo homem ao nascer num cogitável Estado social de direito ${ }^{13}$.

O preâmbulo da Constituição de 1988 é um flagrante exemplo de discurso histórico afirmativo, uma vez que o portal aberto a esses direitos já se encontra aberto (sem ser aqui pleonástico) ante todos, sem que ninguém mais possa abri-lo. Além disso, cabe às três fundamentais funções jurídicas ${ }^{14}$ (legislativa, executiva e jurisdicional) assegurar que todos fiquem perante a lei, sem jamais nela entrarem para fruí-la em seus conteúdos de validade e legitimidade.

Daí, a importância de se ressaltar a total inocuidade de um discurso constitucional, quanto a direitos porventura ali assegurados, se não considerados como conteúdos de um sistema

\footnotetext{
11 A respeito do tema, ver: STEINMETZ, Wilson. Princípio da Proporcionalidade e Atos de Autonomia Privada Restritivos de Direitos Fundamentais. In: SILVA, Virgílio Afonso da (Org.). Interpretação Constitucional, $1^{\text {a }}$ ed.,

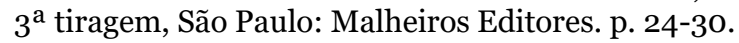

${ }_{12}$ A expressão é utilizada pelo Prof. Rosemiro Pereira Leal, no artigo Direitos Fundamentais do Processo na Desnaturalização dos Direitos Humanos, buscando deixar em evidência que os direitos humanos, conforme ainda falados, pudessem, por si sós, traduzir o seu significado. Assim, o pragma seria o significado do termo direitos humanos, sendo seu alcance concebido a partir da conduta da vida. LEAL, Rosemiro Pereira. Direitos Fundamentais do Processo na Desnaturalização dos Direitos Humanos. Revista da Faculdade Mineira de Direito. Belo Horizonte: PUC Minas, v. 9, n 17, p. 89-100, $1^{\circ}$ sem. 2006.

${ }_{13}$ Sobre o tema, ver: LEAL, Rosemiro Pereira. Direitos Fundamentais do Processo na Desnaturalização dos Direitos Humanos. Revista da Faculdade Mineira de Direito. Belo Horizonte: PUC Minas, v. 9, n 17, p. 89-100, $1^{\circ}$ sem. 2006.

${ }^{14}$ Valemo-nos, neste trabalho, da expressão "três fundamentais funções jurídicas do Estado", utilizada pelo Prof. Dr. Ronaldo Brêtas. BRÊTAS, Ronaldo de Carvalho Dias. Processo Constitucional e Estado Democrático de Direito. Belo Horizonte: Del Rey, 2010. p. 18. Corroboramos com o entendimento do citado autor, para quem a arcaica expressão "divisão de poderes" deve ser banida dos estudos científicos do Direito. Ou, senão expurgada referida expressão, deve ela ser compreendida como conjuntos de órgãos, constitucionalmente dotados de competência para o exercício das atividades ligadas ao Estado. Ou seja, o poder estatal não pode ser dividido (daí a impropriedade da expressão “divisão de poderes”); o que se divide são as atividades. Neste sentido, inclusive, os órgãos estatais encontram-se vinculados ao ordenamento jurídico sendo, portanto, limitados e restringidos por este.
}

Revista de Direito Brasileira | São Paulo, SP | v. 14 | n. 6 | p. 139 - 157 | maio/ago. 2016 
linguístico permanentemente aberto a uma textualização por todos os integrantes de uma comunidade jurídica como conjunto de legitimados ao processo (povo).

Assim, o recinto instrutivo, ao contrário de ser o pragma, deve ser a linguística. A linguagem no Direito, por sua vez, passa a ser processo. Mas, segundo Rosemiro Pereira Leal, tal deve se dar segundo uma teoria da linguagem jurídica ${ }^{15}$. E isso porque não é a fala natural que instaura o exercício dos direitos fundamentais. Assim, enquanto os direitos fundamentais ainda forem concebidos como doações históricas, estará vedada a construção, por uma comunidade jurídica, da linguisticidade juridicamente problematizada.

Nesse sentido, é possível extrair das lições de Del Negri que, para alcançar a legitimidade do direito democrático, deve-se afastar "a linguagem natural (linguagem inerente ao entendimento/pragmática universalizante)" (2011, p. 55).

Caso assim não seja feito, os direitos fundamentais permanecerão com esse significado equivocado, ou seja, não pesquisado, representando mesmo em trajetória de dominação. Daí ser esta a razão pela qual não basta a positivação de direitos: eles devem ser operacionalizados.

Assim, o povo - sujeito constitucional legitimado ao processo - , ainda quando expressa sua vontade soberana por meio de representantes, possui o direito de fiscalizar as formas de manifestação e aplicação de tal poder, sob pena de perda de legitimidade democrática.

Por esse prisma é que, com relação às normas jurídicas, o povo deve ser capaz de recriar, afirmar, negar, debater, discutir, transformar, substituir, destruir ou reafirmar o direito, como seu feitor e intérprete originário.

Não basta, pois, que sejam eleitos (ainda que com o sufrágio universal) parlamentares, se a eles é conferida a permissão para ditarem, sozinhos, a vontade popular.

É preciso, no paradigma democrático, conferir ao destinatário a oportunidade de discutir os fundamentos da norma jurídica para, até mesmo se for o caso, rejeitá-la.

\subsection{DIREITOS FUNDAMENTAIS E GARANTIAS FUNDAMENTAIS}

Direitos fundamentais e garantias fundamentais são tratados pela doutrina, estudos científicos e até mesmo pela prática jurídica como institutos sinônimos. Já de pronto deve-se afirmar que pretendida sinonímia trata-se de um equívoco.

Ronaldo Brêtas de Carvalho Dias analisa referida diferença em sua obra, deixando claro que:

[...] enquanto os direitos fundamentais são os direitos humanos expressamente enumerados e declarados no ordenamento jurídico-constitucional, as garantias constitucionais, por isto, garantias fundamentais, diversamente, compreendem as garantias processuais estabelecidas na própria Constituição (devido processo constitucional ou modelo constitucional do processo) e formadoras de um essencial sistema de proteção aos direitos fundamentais, tecnicamente apto a lhes assegurar plena efetividade. (BRÊTAS, 2010, p. 72).

Assim, pode-se afirmar que as garantias fundamentais pressupõem a existência de um direito fundamental ameaçado ou violado. Ou, nas palavras de Paulo Bonavides, "a garantia meio de defesa - se coloca então diante do direito, mas com este não se deve confundir" (2002, p. 526). Não é por outra razão pela qual o referido autor afirma que

$15 \mathrm{Na}$ obra Processo como teoria da lei democrática, o Professor Rosemiro Pereira Leal expõe: "o lugar do pensar discursivo se inscreve em infinitas possibilidades da fala procedimental processualizada só escolhíveis pelas teoria que possamos previamente conjecturar e coletivamente testificar sobre os fundamentos da linguagem que elegemos para nos reger na construção de sociedades não mitificadas e não metabolizadas em gestos e imagens cujas fundações se edificam no anonimato das técnicas de dominação". LEAL, Rosemiro Pereira. Processo como teoria da lei democrática. Belo Horizonte: Fórum: 2010. p. 64.

Revista de Direito Brasileira | São Paulo, SP | v. 14 | n. 6 | p. 139 - 157 | maio/ago. 2016 
[...] a figura da garantia repercute não somente no campo do direito constitucional de amplitude clássica, senão também dilata à esfera do direito processual, atraindo-o, no tocante à tutela jurisdicional da liberdade e dos direitos fundamentais, para o vasto território onde se renova e amplia cada vez mais o estudo da matéria constitucional. (BONAVIDES, 2002, p. 533).

Enquanto os direitos fundamentais possuem caráter declaratório, as garantias fundamentais, conforme dito acima, possuem natureza de assecuratórias, isto é, direitos que asseguram o direito material propriamente dito. Direitos fundamentais, pois, são o direito à propriedade, liberdade, à vida, privacidade, imagem, honra, etc.

Representante maior das garantias fundamentais constitucionalmente previstas é o devido processo legal, art. $5^{\circ}$, incido LIV da Carta Magna, e este, por conseguinte, incide reflexos diretos em um dos fundamentos da República Federativa do Brasil: a dignidade da pessoa humana.

Destaca-se, aqui, a definição de Alexandre de Moraes:

O devido processo legal configura dupla proteção ao indivíduo, atuando tanto no âmbito material de proteção ao direito de liberdade, quanto no âmbito formal, ao assegurar-lhe paridade total de condições com o Estado-persecutor e plenitude de defesa (direito a defesa técnica, à publicidade do processo, à citação, de produção ampla de provas, de ser processado e julgado pelo juiz competente, aos recursos, à decisão imutável, à revisão cirminal. (MORAES, 2006, p. 94).

E, abrangidos pelo devido processo legal estão o princípio do contraditório, ampla defesa, juiz natural, inafastabilidade da apreciação jurisdicional, razoável duração do processo. Todos esses verdadeiras garantias fundamentais que limitam o poder estatal e equilibram a relação público-particular, que, a princípio, é caracterizada pela subordinação aos corolários da supremacia do interesse público.

Essa subordinação, porém, não pode caracterizar também a relação processual estabelecida entre Estado-juiz e as partes litigantes. E é nesse sentido que o processo constitucional torna a busca pela efetividade jurisdicional um verdadeiro direito fundamental e um dever do Poder Público, na medida em que é no âmbito do processo que direitos são limitados, restringidos, ampliados, suprimidos. É por esta razão que a interferência na esfera dos direitos fundamentais dos jurisdicionados deve ser balizada pela força normativa de princípios constitucionais que, não por acaso, foram, inclusive, positivados, conforme visto acima.

\subsection{DA OPERACIONALIZAÇÃO E CONCRETIZAÇÃO DOS DIREITOS FUNDAMENTAIS}

Ultrapassadas as digressões acima apontadas, forçoso concluir que os direitos fundamentais, muito além de serem constitucionalmente assegurados, devem ser operacionalizados e concretizados. O que significa dizer, conforme ensinamentos de José Alfredo de Oliveira Baracho, que "o reconhecimento dos direitos fundamentais não é suficiente, desde que não vem acompanhado de garantias que assegurem a efetividade do livre exercício de tais direitos" (2008, p. 53).

A positivação dos direitos fundamentais, pois, não representa a condição da materialização dos referidos direitos. Ou seja, os direitos fundamentais, constitucionalmente garantidos, não se auto-operacionalizam nem se autoconcretizam, da mesma forma que, segundo Paulo Bonavides (2002, p. 592), eles sequer se interpretam. 
Insta descatar, também, as lições de Rosemiro Pereira Leal:

Assim, o garantismo em sede constitucional democrática não se configura per se em face de indicação literal de direitos humanos na Constituição ou em face de uma judicacionalidade centrada na filosofia da consciência de guardiães ou depositários infiscalizáveis detentores de uma fundamentação última e irreversível, mas no exercício processual aberto a todos de auto-inclusão executiva pelo devido processo constitucional nos direitos fundamentais prégarantidos, já integralmente resolvidos e acertados no plano da procedimentalidade constituinte. (LEAL, 2005, p. 29). (Grifos no original).

\section{No mesmo sentido, Ronaldo Brêtas de Carvalho Dias afirma que:}

[...] de nada adiantaria um extenso rol de direitos fundamentais, se mecanismos que assegurassem sua concretização também não fossem selecionados e incluídos no texto constitucional, nas situações - e não raras - em que o Estado e os particulares os desconsiderassem. (BRÊTAS, 2010, p. 72).

José Cirilo Vargas, igualmente, compartilha dessa posição, ensinando que a mera previsão e proclamação dos direitos é insuficiente, vez que é preciso "dar os meios para exercêlos, para desfrutá-los", de modo a "afastar a ideia de mero complexo de princípios filosóficos e generosos, sem eficácia executória" (1992, p. 50).

Assim, uma vez já afirmado que a linguagem no Direito passa a ser processo ${ }^{16}$ e que os direitos fundamentais garantidos constitucionalmente somente se efetivam no exercício processual pelo devido Processo Constitucional, através de mecanismos constitucionais, necessário e indispensável se faz o estudo do Processo Constitucional, sobre o qual este trabalho passará a tratar.

\section{O PROCESSO CONSTITUCIONAL}

O Processo Constitucional "17 "se concretiza no modelo constitucional do processo" (BARACHO, 1999, p. 93), visando tutelar o que Baracho denomina de "princípio da supremacia constitucional" (1999, p. 118), desaguando na proteção dos direitos fundamentais.

O mencionado autor ainda afirma que

\footnotetext{
${ }^{16}$ Vide item 3.1.

${ }_{17}$ "É preciso pontuar, a distinção entre direito constitucional processual e direito processual constitucional possui uma história. Ela surge no contexto histórico de criação de uma jurisdição constitucional concentrada. No direito tradicional continental europeu, o juiz comum, assim como o cidadão, deve presumir a constitucionalidade dos atos normativos e das leis e guiar-se pelo entendimento da Corte Constitucional. Em termos kelsenianos, o legislativo e a Corte são autorizados a interpretar a Constituição, o cidadão e o juiz comum não. Questões sobre constitucionalidade ou inconstitucionalidade não devem ser explicitamente tratadas através de processos comuns e nenhum cidadão pode argui-las (pelo menos no modelo clássico) e nenhum juiz ordinário pode pronunciar-se acerca delas. Como diria Peter Häberle, trata-se de uma 'sociedade fechada de intérpretes da constituição'. Uma sociedade fechada criou a doutrina das normas constitucionais programáticas, dos direitos fundamentais em sentido objetivo, que equiparou os direitos a bens negociáveis, que criou a jurisprudência de valores. No Brasil, como nos Estados Unidos, o quadro é outro. Todo cidadão é intérprete da Constituição, qualquer cidadão tem o direito de desobedecer a comandos estatais inconstitucionais e qualquer juiz deve pronunciar-se sobre a inconstitucionalidade desses comandos. Não sem motivo o fato de que para nós, assim como para os norte-americanos, a decisão judicial é declaratória e com efeitos retroativos; a decisão é o resultado do reconhecimento institucional de um direito concreto a desobedecer. Quem desobedece uma lei por considerá-la inconstitucional não é crimionoso; tem razões públicas para isso.” CATTONI, MARCELO. Direito constitucional processual e direito processual constitucional: limites da distinção em face do modelo constitucional brasileiro do controle jurisdicional de constitucionalidade, In CATTONI, Marcelo (Coord.), Jurisdição e hermenêutica constitucional. Belo Horizonte: Mandamentos, 2004. p. 463.
} 
O Processo Constitucional não é apenas um direito instrumental, mas uma metodologia de garantia dos direitos fundamentais. Suas instituições estruturais (jurisdição, ação e processo) remetem-nos à efetivação dos direitos essenciais. (BARACHO, 1999, p. 119).

E continua:

O processo, como garantia constitucional, consolida-se nas constituições do século XX, através da consagração de princípios de direito processual, com o reconhecimento e enumeração de direitos da pessoa humana, sendo que esses consolidam-se pelas garantias que os torna efetivo e exequíveis. (BARACHO, 1997, p. 106).

Pode-se afirmar, portanto, que a Constituição de 1988 tutelou, positivamente, determinados direitos humanos, elevando-os à condição de direitos fundamentais. Mas, além disso, inseriu no ordenamento jurídico uma série de garantias, tais como o devido processo legal (contraditório ${ }^{18}$, isonomia, ampla defesa, fundamentação das decisões), os procedimentos constitucionais (Habeas Corpus, Mandado de Segurança, Habeas Data, Mandado de Injunção), a gratuidade judiciária, o Juízo natural, dentre outros, indispensáveis à efetivação dos mencionados direitos fundamentais. Andolina bem sintetizou essa análise ao afirmar que "O processo jurisdicional coloca-se ao centro de toda a estrutura de atuação das garantias constitucionais" (1997, p. 65).

Considerando-se a conceituação acima apresentada, bem como o fato de ser o Processo Constitucional (seja jurisdicional, legislativo e administrativo) o mais adequado ${ }^{19}$ à concretização do inacabado ${ }^{20}$ Estado Democrático de Direito, forçoso concluir que o atual paradigma do ordenamento jurídico possui grau máximo de importância para a proteção dos direitos fundamentais.

\subsection{O PROCESSO CONSTITUCIONAL COMO INSTITUTO DE PROTEÇÃO DOS DIREITOS FUNDAMENTAIS}

O Processo Constitucional aflora dentro da comunidade estatal. Ele é o mecanismo para proteger direito fundamental ou, como definido por Baracho, é o "instrumento básico de efetivação dos direitos fundamentais e processuais” (2008, p. 56). Baracho, valendo-se dos

18 "O conteúdo mínimo do contraditório não se esgota na ciência bilateral dos atos do processo e na possibilidade de contradita-los, mas faz também depender a própria formação dos provimentos judiciais da efetiva participação das partes. Por isso, para que seja atendido este mínimo, insta a que cada uma das partes conheça as razões e argumentações expendidas pela outra, assim como os motivos e fundamentos que conduziram o órgão judicial a tomar determinada decisão, possibilitando-se sua manifestação a respeito em tempo adequado (seja mediante requerimentos, recursos, contraditas etc.). também se revela imprescindível abrir-se a cada uma das partes a possibilidade de participar do juízo de fato, tanto na indicação da prova quanto na sua formação, fator este último importante mesmo naquela determinada de ofício pelo órgão judicial.” ÁLVARO DE OLIVEIRA, Carlos Alberto. A garantia do contraditório.

19 Referida terminologia foi utilizada pelo Professor Ronaldo Brêtas, na introdução de sua obra Processo Constitucional e Estado Democrático de Direito. BRÊTAS, Ronaldo de Carvalho Dias. Processo Constitucional e Estado Democrático de Direito. Belo Horizonte: Del Rey, 2010. p. 2.

${ }^{20}$ Neste sentido, coadunamos com o entendimento de Marcelo Cattoni, para quem o Estado Democrático de Direito é um "projeto constituinte", por meio do qual se concebe, diariamente, uma "conquista da cidadania". Nesta linha de raciocínio, Cattoni afirma que a referida cidadania seria, inclusive, fruto de "um processo de aprendizado social permanente com o Direito em nossa própria história”. CATTONI DE OLIVEIRA, Marcelo Andrade. A legitimidade democrática da Constituição da República Federativa do Brasil: uma reflexão sobre o projeto constituinte do Estado Democrático de Direito no marco da teoria do discurso de Jurgen Habermas. In: GALLUPO, Marcelo Campos (Coord.). Constituição e democracia: fundamentos. Belo Horizonte: Fórum, 2009, p. 236-259.

Revista de Direito Brasileira | São Paulo, SP | v. 14 | n. 6 | p. 139 - 157 | maio/ago. 2016 
ensinamentos de Eduardo J. Couture, sintetiza, afirmando ser o Processo Constitucional "instrumento de proteção do direito" (1997, p. 105).

Há quem afirme, inclusive, como Flaviane de Magalhães Barros, que “o processo é a garantia constitutiva de direitos fundamentais" (2009, p. 332).

Realizando uma interpretação a contrario sensu da afirmação feita por Rosemiro Pereira Leal $^{21}$, pode-se concluir que o Processo deve ser trabalhado, inclusive, como norma de fruição de direitos fundamentais; direitos tais que, para o mencionado autor, são líquidos, certos e exigíveis.

A jurisdição constitucional, sob o pano de fundo do Estado Democrático de Direito, é, segundo Marcelo Cattoni, "a garantia das condições processuais para o exercício tanto da autonomia pública, quanto da autonomia privada dos co-associados jurídicos" (2009, p. 256259). O que significa dizer que o referido instituto deve ser analisado sob a perspectiva tanto do processo legislativo quanto constitucional, protegendo o processo democrático.

Todavia, o sistema de proteção dos direitos fundamentais, conforme herança científica de José Alfredo de Oliveira Baracho (2008, p. 53), concretiza-se na sua viabilização em sede jurisdicional. E, dentro da perspectiva do Processo Constitucional, a jurisdição deve ser tida como direito fundamental.

Mesmo porque, o art. $5^{\circ}$ da CR88, em seu inciso XXXV, dispõe que a lei não excluirá da apreciação do Poder Judiciário lesão ou ameaça a direito. Assim, a premissa segundo a qual a jurisdição é um direito fundamental advém da própria Carta Constitucional, quando àquela categoria elevou o referido instituto.

Rosemiro Pereira Leal, acerca do instituto da jurisdição constitucional, afirma:

A chamada JURISDIÇÃO CONSTITUCIONAL são os conceitos da lei constitucional vinculantes dos atos decisórios em toda a estabilidade democrática, não significando, como querem os mais ortodoxos, a atividade dos juízes sobre a escritura constitucional [...] (LEAL, 2011, p. 328). (Grifos no original).

Para fruição desse direito fundamental à jurisdição, é necessário valer-se da garantia fundamental $^{22}$ do Processo Constitucional, bem como do devido processo legal (contraditório, isonomia ampla defesa, fundamentação das decisões), que abrange qualquer tipo de processo, seja jurisdicional, legislativo ou administrativo.

Por isso afirma André Del Negri

[...] percebe-se, pois, que a expressão devido processo constitucional é vista como instituição regenciadora de todo e qualquer procedimento (devido processo legal), a fim de tutelar a produção de provimentos, seja administrativo, legislativo ou judicial. (DEL NEGRI, 2008, p. 74).

\footnotetext{
${ }^{21} \mathrm{O}$ citado autor assim expõe em sua obra: "Não é difícil, em nossa área, destacar algumas hipóteses desse fracasso flagelar: [...] e) trabalha-se exclusivamente o 'processo' como normas instrumentais de resolução de conflitos de interesses intersubjetivos historicamente apropriados (lesão ou ameaça a direitos) e não de fruição de direitos fundamentais líquidos, certos e imediatamente exigíveis [...]”. LEAL, Rosemiro Pereira. Modelos Processuais e Constituição democrática. In: MACHADO, Felipe Daniel Amorim e CATTONI DE OLIVEIRA. Marcelo Andrade (Coords.). Constituição e Processo: a contribuição do Processo ao constitucionalismo brasileiro. Belo Horizonte: Del Rey, 2009, p. 284.

${ }^{22}$ A partir das lições de José Alfredo de Oliveira Baracho, o Professor Ronaldo Brêtas de Carvalho Dias assim conceitua a expressão garantia fundamental: "as garantias constitucionais (garantias fundamentais) são meios desenvolvidos pela técnica jurídica moderna, de sorte a controlar a regularidade constitucional dos atos estatais em geral (gênero) e do ato jurisdicional (espécie) em particular." BRÊTAS, Ronaldo de Carvalho Dias. Processo Constitucional e Estado Democrático de Direito. Belo Horizonte: Del Rey, 2010. p. 73.
} 
Das lições de Ronaldo Brêtas de Carvalho Dias pode-se extrair que a jurisdição constitucional deve ser exercida com a observância dos princípios constitucionais, tais como vinculação ao Estado Democrático de Direito, devido processo constitucional e fundamentação das decisões jurisdicionais (BRÊTAS, 2010, p. 169-170).

Neste viés, cria-se para as partes a possibilidade de um debate dialético do processo, deixando à margem qualquer concepção instrumentalista ${ }^{23}$ do processo, que não guarda nenhuma pertinência com o Processo Constitucional, no paradigma do Estado Democrático de Direito.

Diante disso, ousamos afirmar que Hermes Zanetti Júnior se distanciou da concepção constitucionalista do processo ao afirmar ser a sentença um "ato de vontade, portanto ato criativo" (2007, p. 187) do juiz, na medida em que desconsiderou o necessário debate dialético do processo, bem como os princípios norteadores do Processo Constitucional.

Opinião jurídica distanta da de Hermes Zanetti Júnior é apresentada por Dhenis Cruz Madeira:

[...] não se pode admitir a interpretação solitária de uma autoridade supostamente sábia e justa, haja vista que o resultado dessa atividade interpretativa (o provimento) deve ser fruto de uma processualidade dialógica constitucionalizada. (MADEIRA, 2008, p. 36).

Comungando do mesmo entendimento, André Leal:

Se acatarmos que há um devido processo constitucional como matriz principiológica a vincular o exercício legítimo da jurisdição, o devido processo legal (entendido esse como necessária oferta de modelos procedimentais pela lei) só será observado se os modelos apresentados possibilitarem a efetiva participação das partes mediante observância dos princípios do contraditório, da ampla defesa e da isonomia na construção dos procedimentos. (LEAL, 2003, p. $17)$.

Assim, na medida em que o "processo começa a ser percebido como um instituto fomentador do jogo democrático" (NUNES, 2011, p. 40), por certo que ele torna-se também uma garantia ao exercício dos direitos fundamentais, permitindo às partes o devido exercício do contraditório, da ampla defesa, do acesso à jurisdição e da fundamentação das decisões.

Dessa forma, o Processo Constitucional configura verdadeira garantia da Carta Constitucional, com grau máximo de importância, vez que serve de ampla proteção aos direitos fundamentais também previstos constitucionalmente e cuja efetivação não é possível sem que se conceda às partes em processo mecanismos técnicos e procedimentais de dialeticidade e, por que não, confronto entre as teses ali apresentadas e discutidas. Qualquer argumentação em contrário, pois, merece ser afastada, seja porque em confronto com o paradigma do Estado Democrático de Direito, seja porque se apresenta como puro niilismo ${ }^{24}$.

\footnotetext{
${ }^{23}$ Sobre o tema, afirma Lênio Luiz Streck que os defensores da concepção instrumentalista do processo "admitem a existência de escopos metajurídicos, estando permitido ao juiz realizar determinações jurídicas, mesmo que não contidas no direito legislado". STRECK, Lenio Luiz. "Decidir conforme a consciência?" Protogênese do protagonismo judicial. In: MACHADO, Felipe; CATTONI, Marcelo (Coords). Constituição e Processo: entre o direito e a política. Belo Horizonte: Fórum, 2011, p. 219. Assim, não é difícil concluir que a visão instrumentalista do processo não se coaduna com a visão de Processo Constitucional, na perspectiva do Estado Democrático de Direito.

${ }^{24} \mathrm{O}$ termo niilismo deve aqui ser entendido filosoficamente. Segundo o dicionário de Filosofia, é o termo usado com intento polêmico para indicar doutrinas que se recusam a reconhecer realidades ou valores cuja admissão se julga importante. ABBAGNANO, Nicola. Dicionário de Filosofia. Trad. Coordenada e revisada por Alfredo Bosi, $2^{\mathrm{a}}$ ed: São Paulo: Mestre Jou, 1962. p. 682.
}

Revista de Direito Brasileira | São Paulo, SP | v. 14 | n. 6 | p. 139 - 157 | maio/ago. 2016 


\section{CONCLUSÃO}

Diante de todo o exposto, é necessário ressaltar que o constitucionalismo brasileiro, ao instituir o Estado Democrático de Direito como paradigma constitucional, visou não somente limitar o poder estatal como, igualmente e na mesma medida, assegurar a liberdade do sujeito constitucional legitimado ao Processo (povo).

O atual paradigma preza, substancialmente, pela proteção constitucional ao princípio da dignidade da pessoa humana, alimentando, estimulando e promovendo uma verdadeira readaptação das funções do Poder Público à imperiosa necessidade de efetivação das normas constitucionais que prescrevem direitos. A via procedimental que permite a realização dessa perspectiva constitucionalizada do processo é verificada nas garantias fundamentais.

Por esta razão, a Constituição da República Federativa do Brasil, outorgada em 1988, tratou de assegurar tanto direitos fundamentais quanto garantias fundamentais (que são, conforme apresentado, diferentes entre si), de maneira que estas pudessem propiciar a concretização e efetivação daqueles.

A conjugação entre direitos e garantias fundamentais, constitucionalmente assegurados, é feita através do Processo Constitucional — a maior de todas as garantias —, responsável por assegurar a supremacia da Constituição.

O Processo Constitucional garante a fruição do direito fundamental à jurisdição, bem como do devido processo legal (contraditório, isonomia ampla defesa, fundamentação das decisões), que abrange qualquer tipo de processo, seja jurisdicional, legislativo ou administrativo. E, uma vez garantido mencionado direito e à luz da observância aos princípios constitucionais tais como vinculação ao Estado Democrático de Direito, devido processo constitucional e fundamentação das decisões jurisdicionais -, a consequência será uma decisão judicial compartilhada, fruto de um debate dialógico.

Neste viés, conclui-se que os direitos fundamentais, além de positivados, são concretizados e efetivados pelo seu destinatário, que é o povo.

Tendo sido superados os anteriores paradigmas (e considerando aqui as devidas ponderações acima já tratadas), a constitucionalização do processo merece destaque pelo redimensionamento da leitura mesma dos direitos fundamentais, muitos dos quais já consagrados em textos constitucionais anteriores. A efetiva tutela jurisdicional ganha, pois, no Estado Democrático de Direito, nova roupagem, novo significado e traz consigo a proteção adequada e concreta de institutos processuais e direitos materialmente considerados.

A conformação de toda a estrutura normativa, em consequência, exige de todo o Poder Público a inserção e absorção dos princípios mais caros ao atual paradigma, sobretudo aqueles vinculados à dignidade da pessoa humana, à supremacia do interesse público, à atuação da Administração Pública, dos representantes do povo e, também, dos membros do Poder Judiciário.

As implicações e reflexos trazidos pela Constituição de 1988 quanto ao regime jurídico do país incidem, conforme visto, em todas as esferas do Poder Público e devem merecer atenção especial em cada segmento específico, objeto que foge ao intuito do presente trabalho, cuja intenção precípua era analisar, ainda que brevemente, o impacto da proteção constitucional aos direitos fundamentais através da constitucionalização do processo e da existência de garantias fundamentais de natureza processual.

Portanto, o Processo Constitucional é o instituto jurídico responsável por garantir ao sujeito constitucional legitimado ao processo (povo) a proteção e concretização dos direitos fundamentais, garantindo, ainda, a efetivação do Estado Democrático de Direito. 


\section{REFERÊNCIAS}

ABBAGNANO, Nicola. Dicionário de Filosofia. Trad. Coordenada e revisada por Alfredo Bosi, $2^{\mathrm{a}}$ ed: São Paulo: Mestre Jou, 1962.

ÁlVARO DE OLIVEIRA, Carlos Alberto. O juiz e o princípio do contraditório. Revista de Processo, São Paulo: Revista dos Tribunais, ano 18, n. 71, p. 31-38, jul./set. 1993.

O processo civil na perspectiva dos direitos fundamentais. In: Do formalismo no processo civil. 2. ed. rev. São Paulo: Saraiva, 2003.

ANDOLINA, Ítalo Augusto. O papel do Processo na atuação do ordenamento Constitucional e transnacional. Revista de Processo, v. 87, p. 63-69. São Paulo, jul/set. 1997.

ANDRADA, José Bonifácio B. A jurisdição constitucional concentrada no Brasil. Jornal da ANPAF - Associação Nacional dos Procuradores Federais, Brasília - DF, ano VII, n. 31, ago. 2002. Disponível em: 〈http>//www.anpaf.com.br>. Acesso em 11 fev. 2016.

ÁVILA, Humberto. Teoria dos Princípios: da definição à aplicação dos princípios jurídicos. 13a ed rev. e ampl. São Paulo: Malheiros, 2012.

BARACHO, José Alfredo de Oliveira. Direito Processual Constitucional: aspectos contemporâneos. $1^{\mathrm{a}}$ reimp. Belo Horizonte: Fórum, 2008.

1997.

. Processo Constitucional. Revista Forense, v.337, p. 105-123, Rio de Janeiro, jan./mar.

Teoria Geral do Processo Constitucional. Revista da Faculdade Mineira de Direito, v.2, n. 3 e 4, p. 89-154, Belo Horizonte, $1^{\circ}$ e $2^{\circ}$ sem. 1999.

BARROS, Flaviane de Magalhães. O modelo Constitucional de Processo e o Processo Penal: a necessidade de uma interpretação das reformas do Processo Penal a partir da Constituição. In: MACHADO, Felipe Daniel Amorim e CATTONI DE OLIVEIRA. Marcelo Andrade (Coords.). Constituição e Processo: a contribuição do Processo ao constitucionalismo brasileiro. Belo Horizonte: Del Rey, 2009, p. 331-345.

BARROSO, Luís Roberto. O direito constitucional e a efetivação de suas normas: limites e possibilidades da Constituição brasileira. 5. ed. ampl. e atual. Rio de Janeiro: Renovar, 2001.

BEDAQUE, José Roberto dos Santos. Direito e Processo: influência do direito material sobre o processo. 2. ed. São Paulo: Malheiros, 1997.

BONAVIDES, Paulo. Curso de Direito Constitucional. $13^{\mathrm{a}}$ ed. $2^{\mathrm{a}}$ tiragem. São Paulo: Malheiros, 2002.

BRANCO, Paulo Gustavo Gonet. Aspectos da teoria geral dos direitos fundamentais. In: MENDES, Gilmar Ferreira; COELHO, Inocêncio Mártires; BRANCO, Paulo Gustavo Gonet. Hermenêutica constitucional e direitos fundamentais. Brasília: Brasília Jurídica, 2002. 
BRASIL. Constituição (1988). Constituição da República Federativa do Brasil. Brasília: Senado, 1988.

BRÊTAS, Ronaldo de Carvalho Dias. Processo Constitucional e Estado Democrático de Direito. Belo Horizonte: Del Rey, 2010.

. Uma introdução ao estudo do Processo Constitucional. In: CASTRO, João Antônio Lima; FREITAS, Sérgio Henriques Zandona (Coords.). Direito Processual: Estudo Democrático da Processualidade Jurídica Constitucionalizada. Belo Horizonte: Instituto de Educação Continuada, 2012, p. 121-130.

BRINDEIRO, Geraldo. Jurisdição constitucional e o devido processo legal. In: SAMPAIO, José Adércio Leite (Org.). Jurisdição constitucional e direitos fundamentais. Belo Horizonte: Del Rey, 2003.

CARMONA, Carlos Alberto. Considerações sobre a evolução conceitual do processo. Revista de Processo, São Paulo: Revista dos Tribunais, ano 15, n. 57, p. 39-54, jan./mar. 1990.

CARVALHO NETTO; Menelick de.; SCOTTI, Guilherme. Os direitos fundamentais e a (in)certeza do direito: a produtividade das tensões principiológicas e a superação do sistema de regras.Belo Horizonte: Fórum, 2011.

CATTONI DE OLIVEIRA, Marcelo Andrade. A legitimidade democrática da Constituição da República Federativa do Brasil: uma reflexão sobre o projeto constituinte do Estado Democrático de Direito no marco da teoria do discurso de Jurgen Habermas. In: GALLUPO, Marcelo Campos (Coord.). Constituição e democracia: fundamentos. Belo Horizonte: Fórum, 2009, p. 235-262.

Interpretação Jurídica, Processo e Tutela Jurisdicionais sob o Paradigma do Estado Democrático de Direito. In: Revista da Faculdade Mineira de Direito, v. $4, n^{\circ} 7$ e $8,1^{\circ}$ e $2^{\circ}$ sem. 2001.

Tutela jurisdicional e Estado Democrático de Direito: por uma compreensão constitucionalmente adequada do mandado de injunção. Belo Horizonte: Del Rey, 1998.

DEL NEGRI, André. Controle de Constitucionalidade no Processo Legislativo: teoria da legitimidade democrática. $2^{\mathrm{a}}$ ed. rev e ampl. Belo Horizonte: Fórum, 2008.

Processo Constitucional e Decisão Interna Corporis. Belo Horizonte: Fórum, 2011.

Teoria da Constituição e do Direito Constitucional. Belo Horizonte, Fórum, 2009.

DIMOULIS, Dimitri; MARTINS, Leonardo. Teoria Geral dos Direitos Fundamentais. $3^{\text {a }}$ ed. rev., atual. e ampl. São Paulo: Editora Revista dos Tribunais, 2011.

DWORKIN, Ronald. Uma Questão de Princípio. Trad. Luís Carlos Borges. $2^{\mathrm{a}}$ ed. São Paulo: Martins Fontes, 2005.

FILHO, Ruy Alves Henriques. Direitos fundamentais e processo. Rio de Janeiro: Renovar, 2008. 
GOYARD-FABRE, Simone. Os fundamentos da ordem jurídica. Trad. Cláudia Berlener, São Paulo: Martins Fontes, 2002.

LEAL, André Cordeiro. O Contraditório e a Fundamentação das Decisões no Direito Processual Democrático. Belo Horizonte: Mandamentos, 2002.

A teoria do Processo de Conhecimento e a inconstitucionalidade do sistema de provas dos juizados especiais cíveis. Revista do Curso de Direito. Belo Horizonte: Unicentro Isabela Hendrix, v 2, p. 12-19, $2^{\circ}$ sem. 2003.

Modelos Processuais e Constituição democrática. In: MACHADO, Felipe Daniel Amorim e CATTONI DE OLIVEIRA. Marcelo Andrade (Coords.). Constituição e Processo: a contribuição do Processo ao constitucionalismo brasileiro. Belo Horizonte: Del Rey, 2009, p. 283-292.

. Teoria Geral do Processo: primeiros estudos, 10ª ed., Rio de Janeiro: Forense: 2011.

Direitos Fundamentais do Processo na Desnaturalização dos Direitos Humanos. Revista da Faculdade Mineira de Direito. Belo Horizonte: PUC Minas, v. 9, n 17, p. 89-100, $1^{\circ}$ sem. 2006.

. Processo como teoria da lei democrática. Belo Horizonte: Fórum: 2010.

Relativização Inconstitucional da Coisa Julgada: temática processual e reflexos jurídicos. Belo Horizonte: Del Rey, 2005.

MADEIRA, Dhenis Cruz. Processo de Conhecimento e Cognição: uma inserção no Estado Democrático de Direito. Curitiba: Juruá Editora, 2008.

MAGAlHÃES, Joseli Lima (Coord.). Temas de direito processual democrático. Teresina: EDUFPI, 2012.

MARÇAL, Antônio Cota. Princípio - Estatuto, Função e Usos no Direito. In: TAVARES, Fernando Horta (Coord.). Constituição, Direito e Processo: Princípios Constitucionais do Processo. Curitiba: Juruá, 2008.

MARINONI, Luiz Guilherme. A jurisdição no Estado constitucional. Revista Processo e Constituição, Porto Alegre, Faculdade de Direito da UFRGS, n. 2, p. 133-212, mai/2005.

MENDES, Gilmar Ferreira; MÁRTIRES COELHO, Inocêncio e GONET BRANCO, Paulo Gustavo. Curso de Direito Constitucional. $2^{a}$ ed. São Paulo: Saraiva, 2008.

MESQUITA, Gil Ferreira de. Princípios do contraditório e da ampla defesa no processo civil brasileiro. São Paulo: Editora Juarez de Oliveira, 2003.

NUNES, Dierle José Coelho. Processo jurisdicional democrático: uma análise crítica das reformas processuais. $1^{\text {a }}$ ed., $3^{\text {a }}$ reimpr. Curitiba: Juruá, 2011. 
Dierle José Coelho. Apontamentos iniciais de um processualismo constitucional democrático: In: MACHADO, Felipe Daniel Amorim e CATTONI DE OLIVEIRA. Marcelo Andrade (Coords.). Constituição e Processo: a contribuição do Processo ao constitucionalismo brasileiro. Belo Horizonte: Del Rey, 2009, p. 349-362.

OMMATI, José Emílio Medauar. Teoria da Constituição, 2a edição, RJ: Lumen Juris, 2013.

POPPER, Karl Raimund. A lógica da pesquisa científica. Trad. Leonidas Hegenberg e Octanny Silveira da Mota. São Paulo: Kultrix, 2006.

QUEIROZ, Cristina. Direitos fundamentais sociais: questões interpretativas e limites de justiciabilidade. In: SILVA, Virgílio Afonso (Org.). Interpretação constitucional. $1^{\mathrm{a}}$ ed., $3^{\mathrm{a}}$ tiragem. São Paulo: Malheiros Editores, 2010.

SARLET, Ingo Wolfgang. Dignidade da pessoa humana e direitos fundamentais na Constituição Federal de 1988. 3. ed. ver. e atual. Porto Alegre: Livraria do Advogado, 2004.

SOARES, Mário Lúcio Quintão. Teoria do Estado: o substrato clássico e os novos paradigmas como pré-compreensão para o Direito Constitucional. Belo Horizonte: Del Rey, 2001.

SOUSA, Kelen Cristina Fonseca de. O princípio do contraditório: uma reconstrução sob a ótica do paradigma do Estado democrático de direito. 2009. 132f. Dissertação (Mestrado) - Pontifícia Universidade Católica de Minas Gerais, Programa de Pós-Graduação em Direito.

SOUZA NETO, Cláudio Pereira de. Jurisdição constitucional, democracia e racionalidade prática. Rio de Janeiro: Renovar, 2002.

STEINMETZ, Wilson. Princípio da Proporcionalidade e Atos de Autonomia Privada Restritivos de Direitos Fundamentais. In: SILVA, Virgílio Afonso da (Org.). Interpretação Constitucional. $1^{\mathrm{a}}$ ed., $3^{\mathrm{a}}$ tiragem, São Paulo: Malheiros Editores, p. 24-30.

STRECK, Lenio Luiz. "Decidir conforme a consciência?” Protogênese do protagonismo judicial. In: MACHADO, Felipe; CATTONI, Marcelo (Coords). Constituição e Processo: entre o direito e a política. Belo Horizonte: Fórum, 2011, p. 215-250.

, Constituição e Processo, ou de "como discricionariedade não combina com democracia": o contraponto da resposta correta. In: MACHADO, Felipe Daniel Amorim e CATTONI DE OLIVEIRA. Marcelo Andrade (Coords.). Constituição e Processo: a contribuição do Processo ao constitucionalismo brasileiro. Belo Horizonte: Del Rey, 2009, p. 0327.

. Jurisdição constitucional e hermenêutica: uma nova crítica do direito. Porto Alegre: Livraria do Advogado, 2002.

THEODORO JÚNIOR, Humberto. Constituição e Processo: desafios constitucionais da reforma do Processo Civil no Brasil. In: MACHADO, Felipe Daniel Amorim e CATTONI DE OLIVEIRA. Marcelo Andrade (Coords.). Constituição e Processo: a contribuição do Processo ao constitucionalismo brasileiro. Belo Horizonte: Del Rey, 2009, p. 233-263. 
VARGAS, José Cirilo. Processo Penal e Direitos Fundamentais. Belo Horizonte: Del Rey, 1992.

ZANETTI JÚNIOR. Processo Constitucional: o modelo constitucional do Processo Civil Brasileiro. Rio de Janeiro: Lúmen Júris, 2007. 